\title{
The Influence of Interface States at the Schottky Junction on the Large Signal Behavior of Copper-Gate GaN HEMTs
}

\author{
MICHELE ESPOSTO,${ }^{1,2}$ VALERIO DI LECCE, ${ }^{1,3}$ MATTEO BONAIUTI, ${ }^{1,4}$ \\ and ALESSANDRO CHINI, ${ }^{1,5}$ \\ 1.--Information Engineering Department, University of Modena and Reggio Emilia, Strada \\ Vignolese 905, I-41125 Modena, Italy. 2.-e-mail: michele.esposto@unimore.it. 3.—e-mail: valerio. \\ dilecce@unimore.it. 4.—e-mail: matteo.bonaiuti@unimore.it. 5.—e-mail: alessandro.chini@ \\ unimore.it
}

\begin{abstract}
The large signal characteristics of $\mathrm{Cu}$-gate and Ni/Au-gate AlGaN/GaN highelectron-mobility transistors (HEMTs) were compared. The tested devices were fabricated on two different parts of the same wafer following the same fabrication steps, the only difference being in the Schottky contact material. Comparison of the direct-current (DC) and radio frequency (RF) characteristics points out a critical drain current collapse in the $\mathrm{Cu}$-gate devices, with detrimental effects on the RF performance, whereas the Ni/Au-gate HEMTs performed properly during DC, pulsed, and RF measurements. Investigations on the drain current transients and on the $I_{\mathrm{D}}-V_{\mathrm{GS}}$ characteristics, obtained by pulsed signals, suggest the presence of an acceptor trap density in the AlGaN barrier, beneath the $\mathrm{Cu}$ Schottky gate contact, responsible for the poorer performance of the Cu-gate device; an activation energy of $430 \mathrm{meV}$ was extracted. This defectivity seemed to be due to a copper diffusion event, activated by thermal stress induced in the sample during the plasma-enhanced chemical vapor deposition (PECVD) of SiN. Numerical simulations carried out on the tested structure qualitatively support the presence of a trap density explaining the nature of the observed drain current transients.
\end{abstract}

Key words: $\mathrm{AlGaN} / \mathrm{GaN}$ high-electron-mobility transistors (HEMTs), copper diffusion, copper gate, drain current collapse, interface trap, Schottky contact

\section{INTRODUCTION}

The performance and reliability requirements for microwave transistors are becoming increasingly critical in many applications such as mobile communications, broadcasting, and satellite communications. The need for improved efficiency, higher power density, and wider bandwidth is driving significant investments towards microwave devices and systems based on $\mathrm{Si} / \mathrm{SiGe}, \mathrm{GaAs}, \mathrm{SiC}$, and $\mathrm{GaN}$. Large breakdown voltage and high electron velocity make $\mathrm{GaN}$ and $\mathrm{SiC}$ the best candidates; gallium nitride's capability of forming heterojunctions makes it further superior to $\mathrm{SiC}$, and suitable for

(Received February 7, 2012; accepted September 11, 2012; published online October 2, 2012) fabrication of high-electron-mobility transistors (HEMTs). In the last decade, GaN HEMT fabrication has experienced considerable process improvements thanks to technological solutions such as surface passivation, field-plate, and gate recessing. ${ }^{1}$

A high-quality Schottky contact is needed to further increase the performance and reliability of GaN HEMT technology. Several studies have evaluated the improvements achieved by using different gate metals, in order to obtain a high Schottky barrier, low leakage gate current, and stable threshold voltage. ${ }^{2-4}$ The Schottky gate metallization systems investigated in these works involve $\mathrm{Ni} / \mathrm{Au}, \mathrm{WSi}, \mathrm{Ir}, \mathrm{Pd}, \mathrm{Ni}, \mathrm{Mo}$, and Pt. Copper was used too in GaN HEMT technology as a Schottky metal in two different works by Ao et al., ${ }^{5}$ and more recently by Sun et al. ${ }^{6}$ 
In Ref. 5, Cu-gate devices showed a gate leakage current two orders of magnitude lower compared with $\mathrm{Ni} / \mathrm{Au}$-gate structures. This very low value was not far from the case of the pure platinum Schottky contact. ${ }^{7}$ However, differently from in the Pt-gate case, a hypothetical slight reaction between $\mathrm{Cu}$ and $\mathrm{AlGaN}$ or the native oxide on $\mathrm{AlGaN}$ was considered, which could allow better adhesion with no increase of leakage current. The Schottky barrier heights were found to be $1.15 \mathrm{eV}$ for $\mathrm{Cu}$ and $0.97 \mathrm{eV}$ for $\mathrm{Ni} / \mathrm{Au}{ }^{5}$ Such a higher barrier for the $\mathrm{Cu}$-gate device is likely to be one of the physical reasons for the lower leakage current and the positive threshold voltage shift with respect to the $\mathrm{Ni} / \mathrm{Au}$-gate device. The metal stack effect on the current gain cutoff frequency $f_{\mathrm{T}}$ was reported in Ref. 6, and gate leakage current values similar to those obtained in Ref. 5 for the Cu-gate heterostructure field effect transistor (HFET) were found.

Although Cu-gate devices have shown very interesting leakage current values ${ }^{5}$ and small signal parameters,${ }^{6}$ their large signal performance has not been investigated yet. The aim of this paper is to compare the large signal performance of $\mathrm{Cu}$-gate and Ni/Au-gate GaN HEMTs.

As reported below, Cu-gate HEMTs showed a large drain current collapse affecting radio frequency (RF) power performance, probably due to defects located in the AlGaN barrier side underlying the $\mathrm{Cu} / \mathrm{AlGaN}$ interface. The observed nonideal behavior of the $\mathrm{Cu}$-gate device was compared with data extracted by numerical device simulations performed on the tested structure. A qualitative fit between experimental and simulated data was achieved, supporting the hypothesis of the presence of a trap level in the AlGaN barrier, probably caused by a thermally activated copper diffusion event.

\section{DEVICE FABRICATION}

The AlGaN/GaN structure used for this work was grown by metalorganic chemical vapor deposition (MOCVD) on sapphire substrate. The epilayer consisted of a thin AlN nucleation layer, followed by a $2 \mu \mathrm{m}$ insulating GaN buffer and a $20 \mathrm{~nm} \mathrm{Al}_{0.12} \mathrm{Ga}_{0.88} \mathrm{~N}$ barrier. The measured carrier density was about $5.7 \times 10^{12} \mathrm{~cm}^{-2}$. HEMTs were fabricated by Ti/Al/ $\mathrm{Ni} / \mathrm{Au}$ ohmic contact formation, mesa etching, gate contact evaporation, and SiN passivation.

All layers were defined by optical contact lithography. $\mathrm{Ti} / \mathrm{Al} / \mathrm{Ni} / \mathrm{Au}(20 \mathrm{~nm} / 100 \mathrm{~nm} / 20 \mathrm{~nm} / 50 \mathrm{~nm})$ ohmic contacts were thermally evaporated, then annealed at $850^{\circ} \mathrm{C}$ for $30 \mathrm{~s}$. Device mesa isolation was then formed by $\mathrm{SiCl}_{4}$ inductively coupled plasma (ICP) etching with etch depth of about $160 \mathrm{~nm}$. Gate contacts were then formed by thermally evaporating either $\mathrm{Ni} / \mathrm{Au} / \mathrm{Ni}(50 \mathrm{~nm} / 150 \mathrm{~nm} / 50 \mathrm{~nm})$ or $\mathrm{Cu} / \mathrm{Ni}(200 \mathrm{~nm} / 50 \mathrm{~nm})$ on two different parts of the same wafer. Before the gate evaporation, in both cases a surface treatment based on an oxygen plasma descum $(300 \mathrm{mT}, 100 \mathrm{~W}, 15 \mathrm{~s})$ and a deoxidation (HCl:DI 1:3 dip, $20 \mathrm{~s}$ ) was carried out. A SiN layer of about $100 \mathrm{~nm}$ was then deposited by means of plasma-enhanced chemical vapor deposition (PECVD) as a passivation layer.

The gate width and length of the tested devices were $2 \times 100 \mu \mathrm{m}$ and $1.5 \mu \mathrm{m}$, respectively. The gate-drain and gate-source spacing were $2.5 \mu \mathrm{m}$ and $1.5 \mu \mathrm{m}$, respectively.

The measured sheet resistivity and ohmic contact resistance were $1520 \Omega /$ square and $0.3 \Omega \mathrm{mm}$, respectively. Based on the sheet carrier density of the twodimensional electron gas (2-DEG) and on the sheet resistivity, the electron mobility was $720 \mathrm{~cm}^{2} / \mathrm{Vs}$.

\section{EXPERIMENTAL RESULTS}

\section{Gate Leakage Current}

Figure 1 shows the measured gate leakage current at $V_{\mathrm{DS}}=0 \mathrm{~V}$ for both the $\mathrm{Cu}$-gate and the $\mathrm{Ni} / \mathrm{Au}$-gate device. As can be seen, in the case of the $\mathrm{Cu}$-gate device it was about three orders of magnitude lower compared with the Ni/Au-gate device.

From the experimental characteristics in the forward biasing regime for small positive $V_{\mathrm{G}}$, the $\mathrm{Cu}$-gate device seemed to show a higher Schottky barrier (not calculated) compared with the Ni/Augate device.

As demonstrated in Refs. 5, 6, the main advantage of using copper as a Schottky metal is the very low leakage current. Our experimental data are very close to those obtained in Refs. 5, 6 in terms of both the absolute values and the difference between the two Schottky contacts.

\section{AND PULSED-SIGNAL $I-V$ CHARACTERIZATION}

$I_{\mathrm{DS}}-V_{\mathrm{DS}}$ curves for both devices, under both DC and 200-ns pulsed conditions (obtained by pulsing $V_{\mathrm{G}}$ from pinch-off to open channel), are reported in Figs. 2 and 3 , for the $\mathrm{Ni} / \mathrm{Au}$-gate and $\mathrm{Cu}$-gate HEMT, respectively.

Under DC conditions, both devices show a similar current density. Comparing the DC and pulsed $I-V$

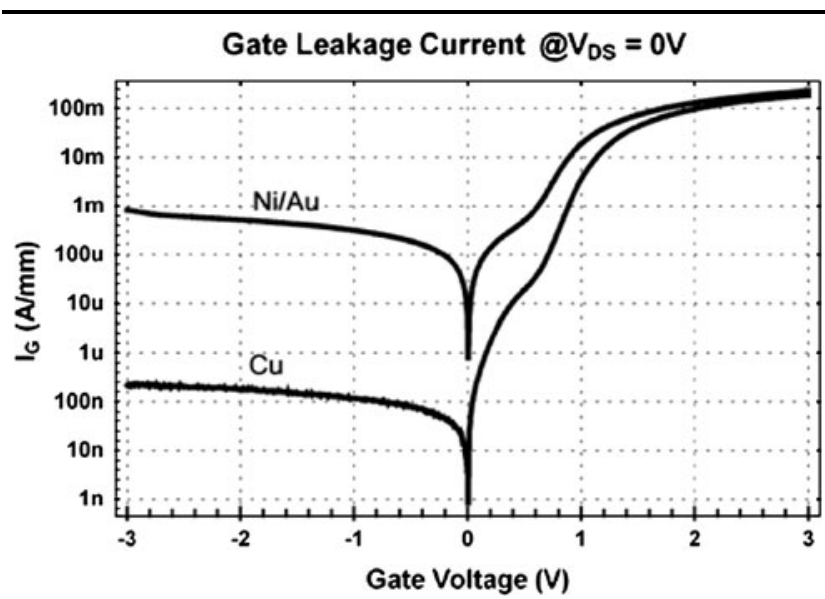

Fig. 1. Comparison of gate leakage current for $\mathrm{Cu}$-gate and $\mathrm{Ni} / \mathrm{Au}$ gate devices; measurement performed at $V_{\mathrm{DS}}=0 \mathrm{~V}$ 


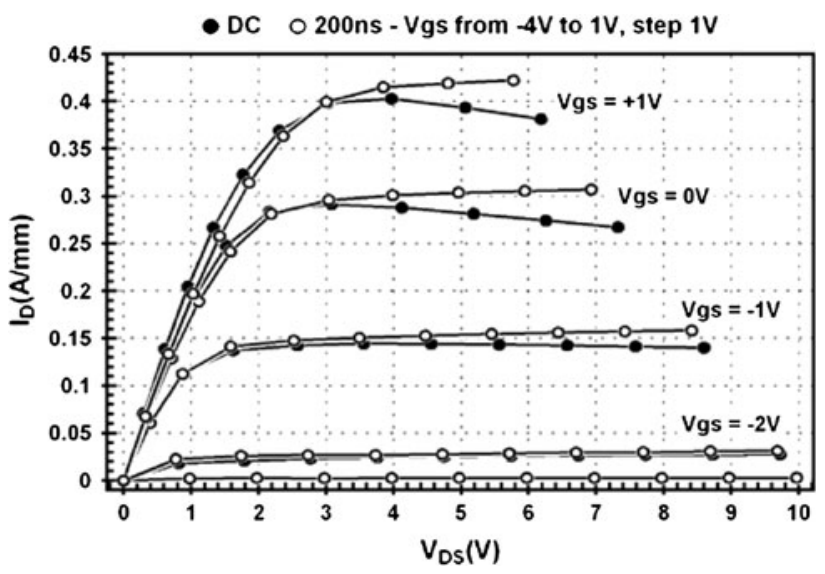

Fig. 2. $I_{D}-V_{D S}$ characteristics of Ni/Au-gate HEMT obtained by DC (filled circles) and pulsed (empty circles) signals. Pulse width is $200 \mathrm{~ns}$. $V_{\mathrm{GS}}$ from $-4 \mathrm{~V}$ to $1 \mathrm{~V}$, step $1 \mathrm{~V}$.

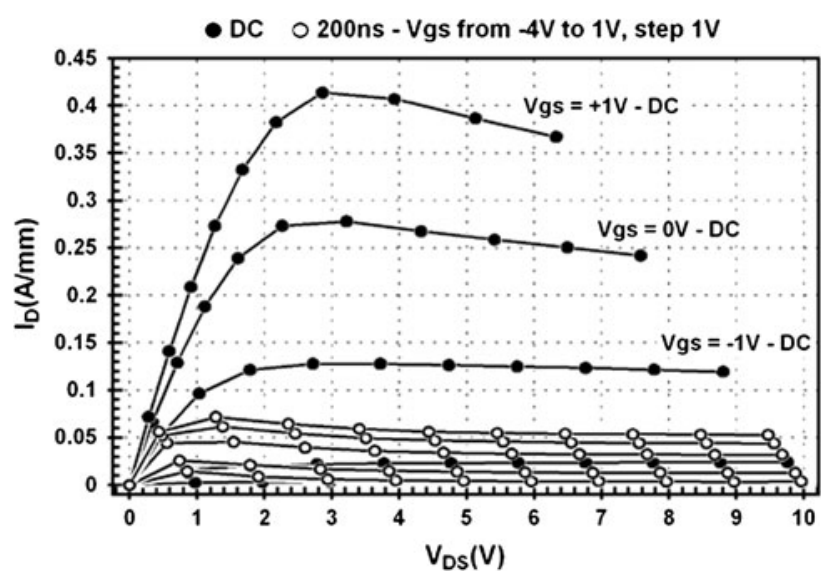

Fig. 3. $I_{D}-V_{D S}$ characteristics of Cu-gate HEMT obtained by DC (filled circle) and pulsed (empty circle) signals. Pulse width is $200 \mathrm{~ns}$. $V_{\mathrm{GS}}$ from $-4 \mathrm{~V}$ to $1 \mathrm{~V}$, step $1 \mathrm{~V}$.

characteristics, no dispersion phenomena are observed for the $\mathrm{Ni} / \mathrm{Au}$-gate device, whereas a severe current collapse is noticeable under pulsed conditions for the $\mathrm{Cu}$-gate device.

This critical current collapse affecting the Cu-gate device suggests that trapping phenomena are likely to prevail in the transient behavior. At the same time, the absence of dispersion in the $\mathrm{Ni} / \mathrm{Au}$ device suggests that no significant carrier trapping phenomena affect the gate-drain or gate-source access region. ${ }^{8}$ Since the passivation process was the same for both samples, trapping phenomena at the $\mathrm{Cu} / \mathrm{AlGaN}$ Schottky junction could be the main reason for the current collapse.

\section{RF POWER MEASUREMENT}

To estimate how the drain current collapse affects the $\mathrm{Cu}$-gate device $\mathrm{RF}$ performance, continuouswave (CW) load-pull power measurements at $2 \mathrm{GHz}$

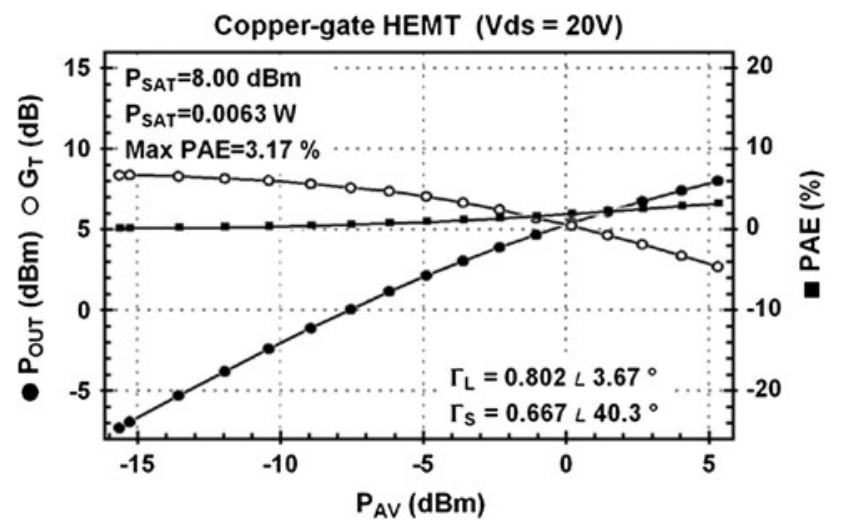

Fig. 4. Load-pull characterization of the Ni/Au-gate HEMT at $2 \mathrm{GHz}$. Biasing condition and other significant values are reported in the figure.

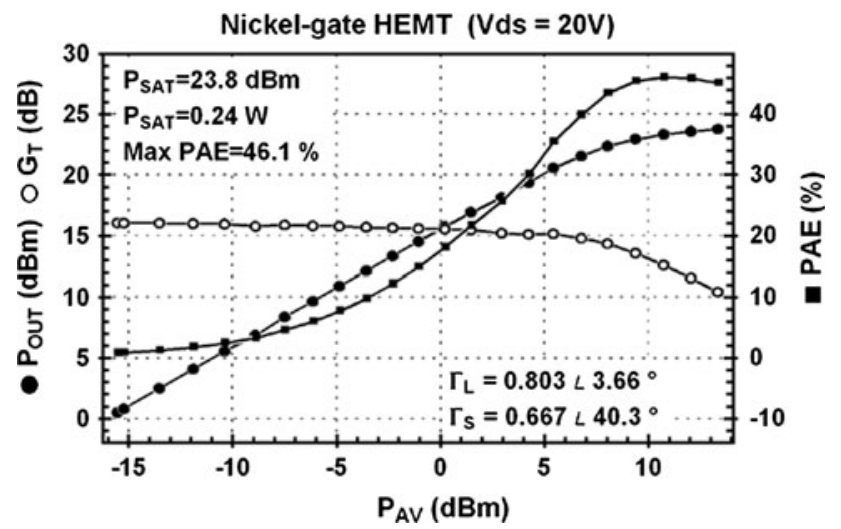

Fig. 5. Load-pull characterization of the Cu-gate HEMT at $2 \mathrm{GHz}$. Biasing condition and other significant values are reported in the figure.

were carried out. The results for a quiescent drain bias of $20 \mathrm{~V}$ are reported in Fig. 4 for the Ni/Au-gate device, and in Fig. 5 for the Cu-gate device.

The Ni/Au-gate device yielded a saturated output power of $1.2 \mathrm{~W} / \mathrm{mm}$ with a maximum power added efficiency (PAE) of $46 \%$ and a small signal power gain of $16 \mathrm{~dB}$. Even though the output power density seems to be much lower compared with state-of-theart passivated devices-in excess of $10 \mathrm{~W} / \mathrm{mm}^{9,10}$-it is in agreement with the theoretical limits, being dominated by the drain current density.

The Cu-gate HEMT yielded a saturated output power of $31.5 \mathrm{~mW} / \mathrm{mm}$ with a maximum PAE of $3 \%$ and a small signal power gain of $8.3 \mathrm{~dB}$.

As expected, the current collapse observed during pulsed measurements is the dominant factor in the $\mathrm{RF}$ behavior of the $\mathrm{Cu}$-gate device. The significant difference in the large signal $\mathrm{RF}$ performance between the $\mathrm{Ni} / \mathrm{Au}$-gate and $\mathrm{Cu}$-gate devices indicates again that some trapping phenomenon at the $\mathrm{Cu} / \mathrm{AlGaN}$ interface must be responsible for the 
poorer power performance observed for the $\mathrm{Cu}$-gate device.

\section{INTERFACE TRAP CHARACTERIZATION}

Measurement of the $I_{\mathrm{D}}-V_{\mathrm{GS}}$ characteristics for negative $V_{\mathrm{GS}}$ values was then performed. The drain terminal was connected to a constant $V_{\mathrm{DD}}=3 \mathrm{~V}$ power supply through a $50 \Omega$ resistor, and the gate terminal was pulsed from $0 \mathrm{~V}$ to negative values. A comparison between the $\mathrm{DC}$ and pulsed $I_{\mathrm{D}}-V_{\mathrm{GS}}$ characteristics for a $\mathrm{Cu}$-gate device, with pulse widths ranging from $5 \mu$ s to $500 \mathrm{~ms}$, is depicted in Fig. 6. The same measurement was carried out on a $\mathrm{Ni} / \mathrm{Au}$-gate HEMT and is reported in Fig. 7. As can be seen, no discrepancy between the DC and pulsed characteristics was found for the $\mathrm{Ni} / \mathrm{Au}$-gate device, whereas the behavior of the Cu-gate device in pulsed conditions confirms the presence of the trapping phenomena previously mentioned: modulation of the drain current in low reverse biasing

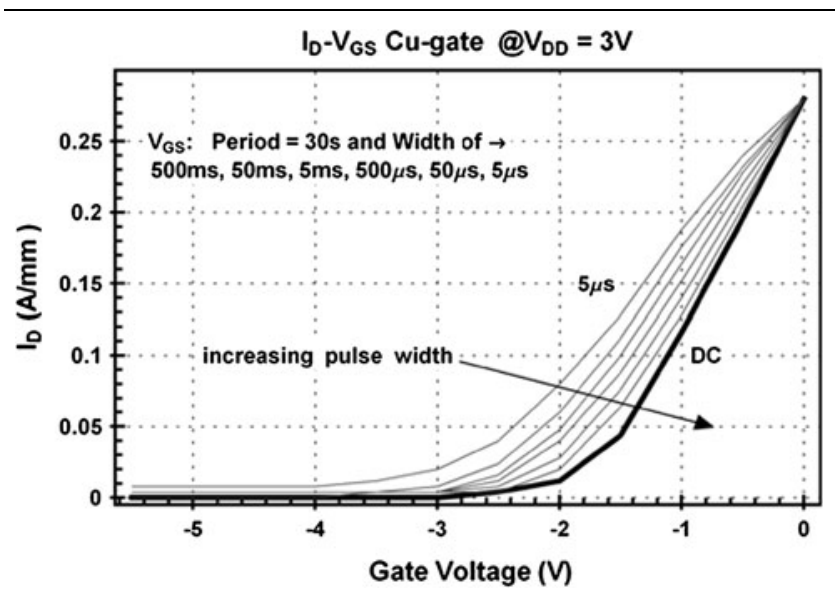

Fig. 6. Cu-gate HEMT $I_{D}-V_{G S}$ measurement, pulsing $V_{G S}$ from DC to $5 \mu$ s pulse width (PW). All PW values are reported in the figure.

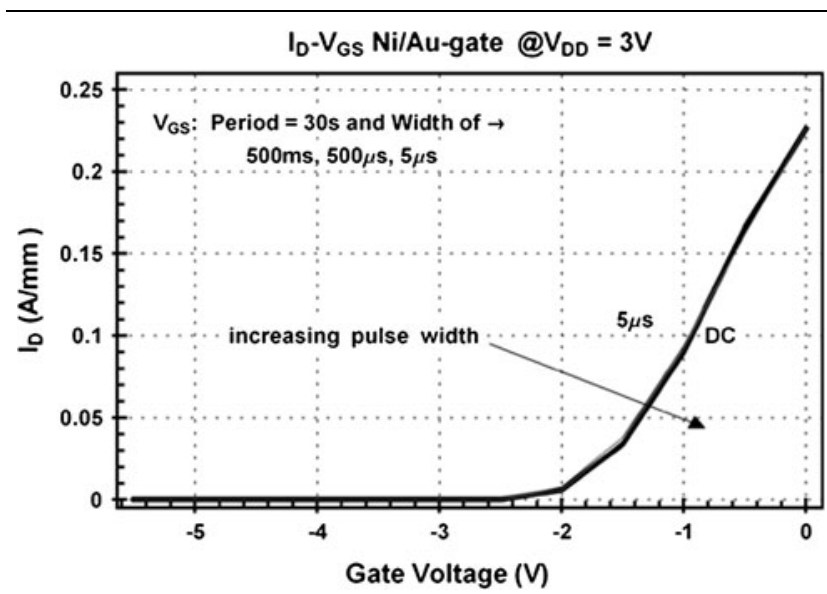

Fig. 7. Ni/Au-gate HEMT $I_{D}-V_{\mathrm{GS}}$ measurement, pulsing $V_{\mathrm{GS}}$ from $\mathrm{DC}$ to $5 \mu \mathrm{s}$ pulse width (PW). All PW values are reported in the figure. conditions is noticeable, as well as incomplete depletion of the 2-DEG channel for high reverse bias voltages.

To evaluate the activation energy of these traps, we acquired turn-off drain current transients by applying to the gate a $0 \mathrm{~V}$ to $-1 \mathrm{~V}$ square wave with a period of $80 \mathrm{~s}$ and duty cycle of $50 \%$, at different temperatures. $V_{\mathrm{DD}}$ was adjusted so that the steadystate $V_{\mathrm{DS}}$ at the end of the turn-off pulse was kept constant at $3 \mathrm{~V}$. The temperature was increased from $90^{\circ} \mathrm{C}$ to $150^{\circ} \mathrm{C}$, in $20^{\circ} \mathrm{C}$ steps.

The acquired transients were then fitted by the stretched-exponential function suggested in Ref. 8:

$$
I(t)=I_{0}+I_{1} \cdot \operatorname{Exp}\left(-\frac{t}{\tau}\right)^{\beta}
$$

where $\beta$ is the stretching parameter.

The extracted activation energy was about $0.43 \mathrm{eV}$. A normalized turn-off drain current transient at $130^{\circ} \mathrm{C}$ on a semilogarithmic scale and the derived Arrhenius plot are shown in Fig. 8.

A possible physical explanation for the drain current behavior could be the presence of an acceptor trap density, with a hole emission event corresponding to the turn-off transient, located in the part of the $\mathrm{AlGaN}$ barrier facing the $\mathrm{Cu} / \mathrm{AlGaN}$ Schottky contact.

The energy band model adopted for the $\mathrm{Cu} / \mathrm{Al}-$ $\mathrm{GaN} / \mathrm{GaN}$ structure and the time evolution for the turn-off transient are reported in Fig. 9. In the initial equilibrium state $V_{\mathrm{GS}}=0 \mathrm{~V}(t=0-)$. In the turn-off transient, an abrupt increase in the reverse biasing signal $\left(V_{\mathrm{GS}}=V_{\mathrm{R}}\right)$ occurs at $t=0$ : the nonequilibrium state $(t=0+)$ evolves into the final equilibrium state at $t=\infty$. When the gate voltage becomes more negative, the transient behavior is driven by the hole emission. This influences the trapped charge in the defective region, as well as the formation and depletion of the 2-DEG. In the end, the turn-off transient gives rise to a detrapping

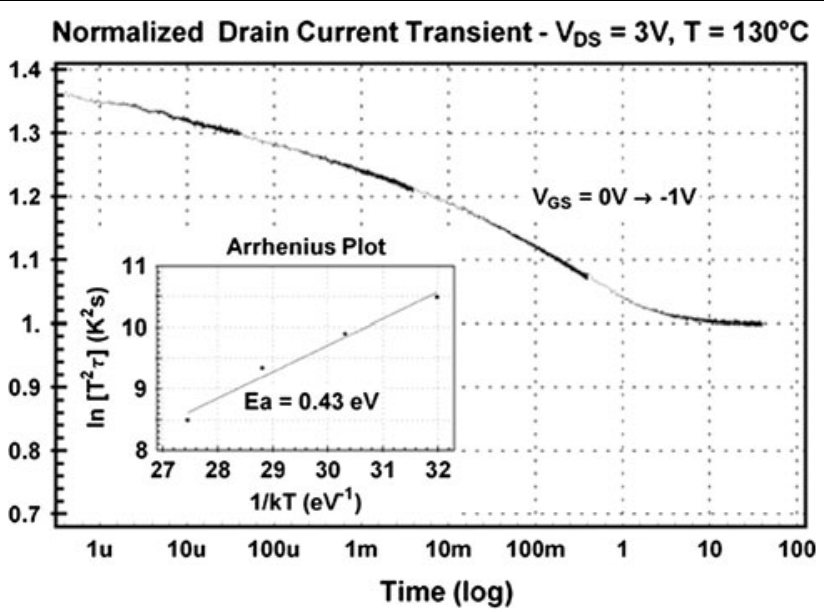

Fig. 8. Normalized drain current transient, at $V_{\mathrm{DS}}=3 \mathrm{~V}, T=130^{\circ} \mathrm{C}$, on logarithmic time scale. Inset: derived Arrhenius plot. 
event for the acceptor trap density, with a consequent depletion of the 2-DEG beneath the gate contact and a decrease in drain current.

\section{NUMERICAL SIMULATIONS}

To correlate the measured drain current transients as reported in Fig. 8 with the effects of the mentioned trap density, 2-D numerical device simulations were carried out using Dessis 8.0 software (Synopsys Int. Ltd.).

The aim of these simulations was to obtain simulated drain current transients qualitatively fitting the measured ones. The simulated structure was the one reported in Fig. 9, with a trapping region located in the $\mathrm{AlGaN}$ barrier, at the $\mathrm{Cu} / \mathrm{AlGaN}$ interface, facing the Schottky junction. Different defective region thicknesses and trap concentrations were considered. The trap density energy level was set to $0.43 \mathrm{eV}$ below the conduction-band edge, as experimentally measured.

In Fig. 10 the normalized simulated drain current transients are depicted for a constant trap concentration of $2 \times 10^{21} \mathrm{~cm}^{-3}$ and different defective region thicknesses $(4 \mathrm{~nm}, 6 \mathrm{~nm}, 8 \mathrm{~nm}$, and $10 \mathrm{~nm})$.

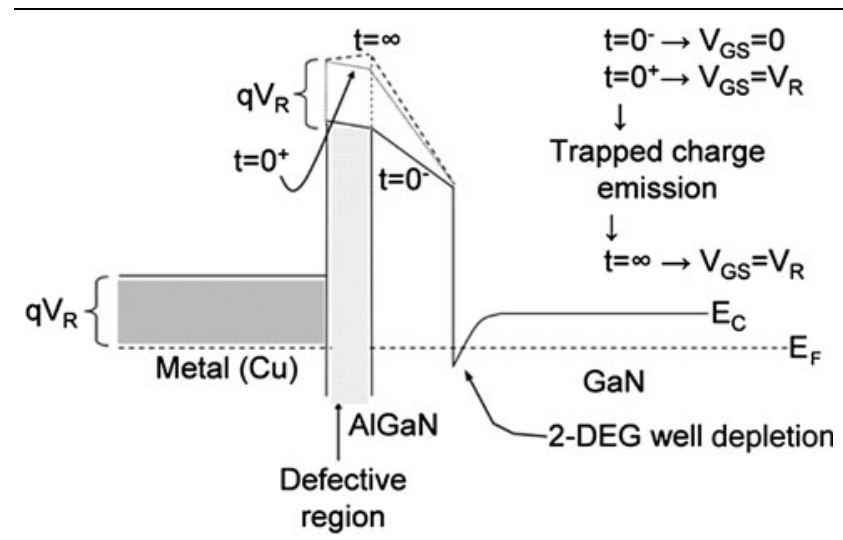

Fig. 9. Energy band diagram of Cu/AIGaN/GaN heterostructure. Time evolution of the turn-off transient is reported.

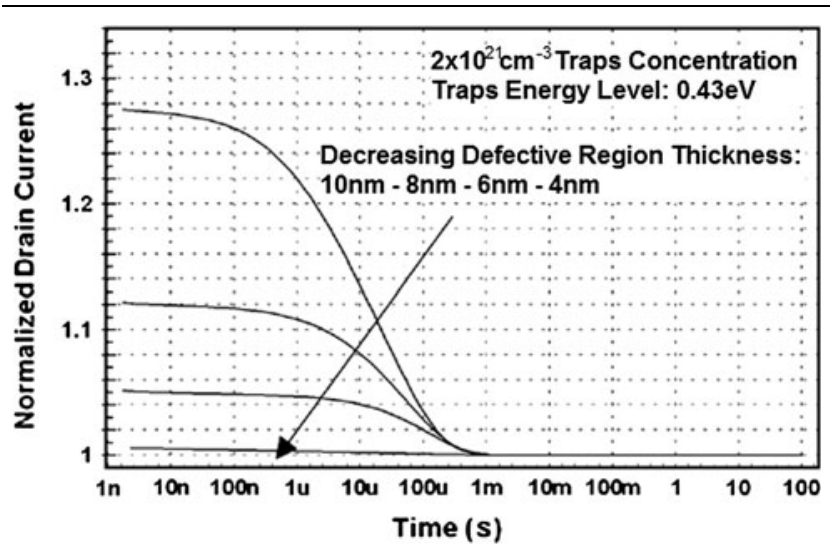

Fig. 10. Normalized simulated drain current transients at constant trap concentration.
As can be seen, the lower the defective region thickness, the smaller the difference between the initial and final value of the drain current.

Figure 11 shows the simulated drain current transients for a constant defective region thickness of $8 \mathrm{~nm}$ and different trap concentrations $\left(0.5 \times 10^{21} \mathrm{~cm}^{-3}, 1 \times 10^{21} \mathrm{~cm}^{-3}, 2 \times 10^{21} \mathrm{~cm}^{-3}\right.$, and $\left.5 \times 10^{21} \mathrm{~cm}^{-3}\right)$. As clearly appears, the lower the trap density, the lower the initial current level in the transient.

In both cases (constant trap concentration and constant defective region thickness), the system's physical behavior reasonably supports a qualitative fitting of the experimental data. This also validates the hypothesis about the presence of a defective region in the $\mathrm{AlGaN}$ side of the $\mathrm{Cu} / \mathrm{AlGaN}$ Schottky interface.

\section{DISCUSSION}

The presented electrical investigation does not provide details about the origin of the defective region under consideration. The scenario from which this defectiveness could arise must involve all the possible copper interactions. We here propose two possible contributions: The main one could be a copper-AlGaN interaction, and the second one could be SiN passivation layer degradation due to the rapid diffusion of copper along PECVD-SiN film microdefects. ${ }^{11}$

No studies on the interaction between copper and GaN have been reported yet, therefore we discuss the physical mechanisms underlying the observed phenomena by referring to the literature about the interaction between $\mathrm{Cu}$ and $\mathrm{GaAs}$ and, because of the $\mathrm{SiN}$ passivation, between $\mathrm{Cu}$ and $\mathrm{Si}$.

As widely reported by several authors, copper diffuses very quickly into silicon and gallium arsenide in the absence of a diffusion barrier. ${ }^{12-15}$ For this reason, studies have investigated the effects of different $\mathrm{Cu}$ diffusion barrier materials for both $\mathrm{Si}$ and GaAs. One of them is tantalum, ${ }^{16}$ which does not form compounds with copper. However, in our

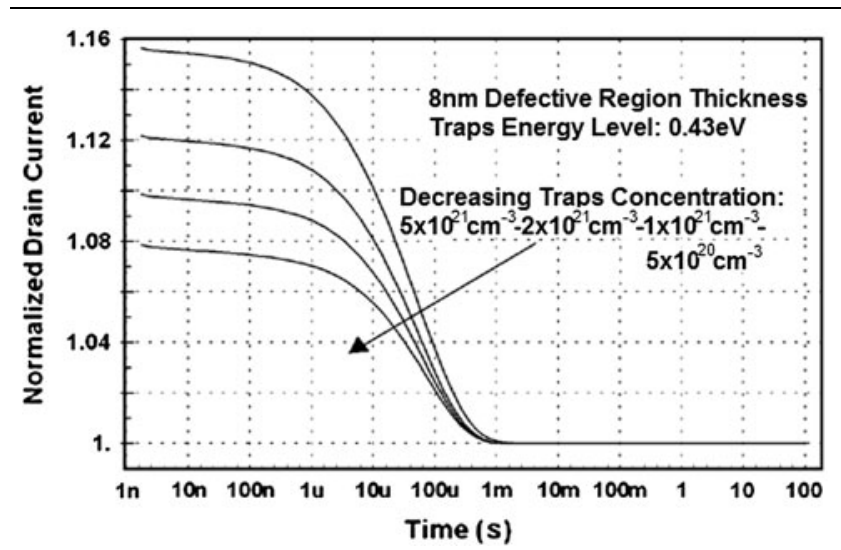

Fig. 11. Normalized simulated drain current transients at constant defective region thickness. 
devices, copper faces both $\mathrm{AlGaN}$ and $\mathrm{SiN}$ with no diffusion barrier.

The $\mathrm{Cu}-\mathrm{SiN}$ interaction is negligible because of the very small area of the copper surface exposed to $\mathrm{SiN}-\mathrm{a}$ few hundred nanometers at the edges of the $\mathrm{Cu} / \mathrm{Ni}$ gate stack. In the end, assuming a similar behavior for copper interacting either with GaAs or $\mathrm{GaN}$, the diffusion in the AlGaN barrier would be the dominant phenomenon, because of the relatively high temperature reached by the samples during the PECVD SiN deposition.

The estimated temperature reached by the PECVD reactor chamber during the deposition was $280^{\circ} \mathrm{C}$, and the average $\mathrm{SiN}$ deposition rate was approximately $0.25 \mathrm{~nm} / \mathrm{s}$. Therefore, for $100 \mathrm{~nm} \mathrm{SiN}$ deposition, the total unintentional annealing time was about $400 \mathrm{~s}$.

Unfortunately, most of the experiments reported in the literature about $\mathrm{Cu}$ diffusion in $\mathrm{GaAs}$ involve higher temperatures (above $400^{\circ} \mathrm{C}$ ) and longer annealing times. ${ }^{17-20}$ All these cited works report very detailed results in terms of diffusion rates/ velocities, but our electrical-based investigation does not provide us with many details about the diffusion event. Even though, according to the literature, copper does appear to be a very diffusive metal, our hypothesis about its diffusion mechanism assuming a similar interaction with $\mathrm{GaAs}$ and $\mathrm{GaN}$ can be validated only in a qualitative way.

Investigations on material quality are required to determine whether and how much the $\mathrm{Cu}$ species penetrated the $\mathrm{AlGaN}$ barrier.

\section{CONCLUSIONS}

An evaluation of the effects of the use of copper as a gate metal in $\mathrm{AlGaN} / \mathrm{GaN}$ HEMTs was performed by comparing a $\mathrm{Ni} / \mathrm{Au}$-gate and a $\mathrm{Cu}$-gate passivated device, fabricated on two different parts of the same wafer following the same processing steps, the only difference being in the Schottky contact formation. Complete DC and RF characterization was carried out for both devices, revealing a detrimental drain current collapse in the $\mathrm{Cu}$-gate device. The absence of any dispersion phenomena in the $\mathrm{Ni} / \mathrm{Au}$ gate device, and the analysis of the drain current transients, revealed the presence of an acceptor trap density in the $\mathrm{AlGaN}$ barrier beneath the $\mathrm{Cu} / \mathrm{AlGaN}$ Schottky junction, with an activation energy of about $0.43 \mathrm{eV}$, probably due to a $\mathrm{Cu}$ diffusion event. Numerical simulations performed on the tested structure qualitatively support the presence of such a trap density.

\section{ACKNOWLEDGEMENTS}

This work was supported in part by the Italian Ministry of Education, University, and Research (MIUR) under the FIRB 2006 Project "Enabling technologies, characterization, and modeling for wideband reconfigurable integrated electronic components for high frequency applications," and under the PRIN 2007 Project "GaN wideband microwave and $\mathrm{mm}$-wave integrated circuits for low-noise and high-power subsystems." The authors would like to thank Prof. Massimo De Vittorio, Dr. Adriana Passaseo, and Dr. Stefano De Guido (National Nanotechnology Laboratory NNL-University of Salento, Lecce, Italy).

\section{REFERENCES}

1. U.K. Mishra, L. Shen, T.E. Kazior, and Y.-F. Wu, Proc. IEEE 96, 287 (2008)

2. A.C. Schmitz, A.T. Ping, M. Asif Khan, Q. Chen, J.W. Yang, and I. Adesida, J. Electron. Mater. 27, 255 (1998).

3. G.H. Jessen, R.C. Fitch, J.K. Gillespie, G.D. Via, N.A. Moser, M.J. Yannuzzi, A. Crespo, R.W. Dettmer, and T.J. Jenkins, Proc. IEEE GaAs Symp., Nov. 2003, pp. 277-279.

4. Y. Yamashita, A. Endoh, K. Ikeda, K. HikosakaL, T. Mimura, M. HigashiwakiL, T. Matsui, and S. Hiyamizu, J. Vac. Sci. Technol. B, Microel. Process. Phenom. 23, L13 (2005).

5. J.-P. Ao, D. Kikuta, N. Kubota, Y. Naoi, and Y. Ohno, IEEE Electron. Dev. Lett. 24, 500 (2003).

6. H.F. Sun, A.R. Alt, and C.R. Bolognesi, IEEE Electron. Dev. Lett. 28(5), May 2007.

7. L. Wang, M.I. Nathan, T.-H. Lim, M.A. Khan, and Q. Chen, Appl. Phys. Lett. 68, 1267 (1996).

8. R. Vetury, N.Q. Zhang, S. Keller, and U.K. Mishra, IEEE Trans. Electron. Dev. 48, 560 (2001).

9. Y.-F. Wu, D. Kapolnek, J. Ibbetson, N.-Q. Zhang, P. Parikh, B. Keller, and U.K. Mishra, 1999 IEDM Technical Digest, Dec. 1999, pp. 925-927.

10. J.R. Shealy, V. Kaper, V. Tilak, T. Prunty, J.A. Smart, B. Green, and L.F. Eastman, Condens. Matter 14, 3499 (2002)

11. M. Hiroshi, K. Hisao, and H. Kenji, J. Appl. Phys. 81, 7746 (1997).

12. E.R. Weber, Appl. Phys. A 30, 1 (1983).

13. A. Cros, M.O. Aboelfotoh, and K.N. Tu, J. Appl. Phys. 67, 3328 (1990).

14. C.-A. Chang, J. Appl. Phys. 67, 566 (1990).

15. P.H. Wohlbier, (Trans. Tech, OH, 1975), Vol. 10, pp. 89-91.

16. C.-Y. Chen, L. Chang, E.Y. Chang, S.-H. Chen, and D.-F. Chang, Appl. Phys. Lett. 77(21), Nov. 20, 2000.

17. D.A. MacQuistan and F. Weinberg, J. Cryst. Growth 110 745 (1991).

18. R.N. Hall and J.H. Racette, J. Appl. Phys. 35, 379 (1964).

19. C.S. Fuller, J.M. Whelan, and J. Phys, Chem. Solids 6, 173 (1958).

20. Y. Furukawa, J. Phys. Chem. Solids 26, 1869 (1965). 